\title{
REPLY TO CRITICAL RESPONSE
}

\author{
Peter Jan Margry, University of Amsterdam, Meertens Institute
}

A short comment is actually not sufficient to react to all the implications and assumptions brought up in the extensive follow-up by Salemink and Verrips. However, I think I should respond to the central issues to which they object. Hence, I will focus on the mentioned imprecisions and the issue of citation, on the reframing by both authors of my text as an intentional divisive narrative between disciplines, and on the suggestion of blurring and anachronizing the idea of a joint publication.

First of all, it must be made clear that I was asked to write a personal narrative on the Bax case and not a full annotated research article dealing with all persons involved and all letter writing acts or criticisms, for which presumed "lack", "keeping things silent", or "glaring lack of precision" the authors reproach me on various places. That would have resulted in another format and genre of text, not to mention dozens of pages more.

1. I do admit that I did not ask for permission to cite from our emailing in this case. Further, there are indeed imprecisions in my text, but much less than they suggestively state. Indeed, there is no formal Ph.D. oath in the Dutch doctoral programme, but there is a practice of requesting the new doctor to work within the ethics of science. I concede that this metaphor, as well as my ascribing of the belief in such an "oath" to both authors, is uncareful phrasing.

2. I am also a member of anthropological associations, I write and review for anthropological journals and publishers, I work regularly with anthropologists, visit their congresses. I have no interest in constructing a divisive narrative between anthropology and ethnology. In my article I only wanted to point out that there are also still (productive) differences between the disciplines and that because of the diachronic perspective of historians and ethnologists, it was, in my view, obvious to them that Bax was a fantasist much earlier than what I experienced among anthropological colleagues.

3. This leads directly to the next point: I always refrained from writing an article by myself to reveal the misconduct of Bax precisely because of my training as an historian. I felt that, in the scholarly world, it is not done and even risky to measure someone from another discipline. I did not want to silence things or refrain from taking action, as Verrips and Salemink suggest. Especially for this reason, I approached both of these anthropologists to do so jointly. The recollection of what happened then is now subject to our different interpretations. We came close to writing that article at one point and, indeed, Focaal was the possible podium, but both of these scholars kept hesitating. Verrips and Salemink now make it clear that this was primarily due to illness. They did not tell me this was the reason at the time. Instead, in our ongoing communication in the year 2008, Verrips told me (more than once, in both email [4 September 2008] and person) that he had indeed his doubts about Bax, but that he was also afraid of being wrong, risking accusations of slander. Salemink expressed no doubt about the fraud of Bax, but he also refrained from writing. To explain why, I indeed used an email exchange between us from 2012 for an underpinning of the situation in 
2008 , as that reflected closely what we spoke about in 2008, mostly on the telephone. On 23 September 2008, Salemink apologised to me by email for not having discussed the writing of the article anymore and promised to call me later, which he never did.
He only wrote later the same day one last email mentioning that he wants to be very careful and avoid a scandal. In the end, it was only after the publication by the journalist to whom I gave my Bax files in 2012 that contact with Salemink resumed. 